\title{
Porch Placemaking. How In-between Spaces Work During and After the COVID-I 9 Pandemic
}

\author{
Koichiro Tamura \\ Sotonoba, Japan \\ tamurakoichiro@gmail.com
}

\begin{abstract}
This article illustrates the concept of "porch placemaking" emerging in various neighbourhoods in the world during the COVID- 19 pandemic. While people face difficulty going to and staying in public spaces, they invent micro-intervention to socialize with others at their front porch, balcony, or window with a lighter, quicker, cheaper approach. These spaces are in-between spaces interfacing private and public realms. Porch placemaking can positively influence socially, culturally, and mentally in neighbourhoods, but it seems conditioned to apply by physical, natural, and social settings.

Porch placemaking is a quick and improvisational reaction to the pandemic. However, it could be an effective way to enhance a sense of neighbourhood even after the pandemic. This article discusses ways to sustain and expand the practice.
\end{abstract}

Keywords: porch placemaking, in-between space, soft edge, transitional space, community resilience

To cite this article:

Tamura, K. (2020). Porch Placemaking. How In-between Spaces work During and After the COVID-I 9 Pandemic, The Journal of Public Space, 5(3), I83-190, DOI 10.3289I/jps.v5i3.1376

This article has been double blind peer reviewed and accepted for publication in The Journal of Public Space.

(c) (5) This work is licensed under a Creative Commons Attribution - Non Commercial 4.0 International License https://creativecommons.org/licenses/by-nc/4.0/ 


\section{Introduction}

The global pandemic of COVID-19 has changed daily lives in cities; many cities have restricted going out from home or recommended staying there for a few months as of May 2019. Consequently, city dwellers avoid mingling and staying long in public spaces and lost chances of refreshing themselves and socializing with others. This situation is stressful for people, and they have desired a space to escape from their indoor private space and substitute parks and open spaces for social wellbeing.

This article documents and analyses how people react to the current situation under stay-home order and physical distancing, based on observation of the author's neighbourhoods, collecting international cases on online media, and forum discussion with participants worldwide.

\section{Active use of porches and around across the world}

As a reaction to the situation, many people in the world use their porch, front yard, balcony, or windows to entertain themselves and others, share a positive mood, and feel connected to each other.

For instance, residents in the Oakwood neighbourhood, Raleigh, NC, came out to their porch to sing, make music, make noise, and connect from a distance (Govan, 2020). In doing so, some of them placed messages such as "howdy" and "thank you" there to communicate with others. Another example appeared on a balcony, porches, front yards, and sidewalks in Buffalo, NY. Residents there gathered across a street had a "social distancing dance party" every evening. Even though the state was one of the most severe pandemic epicentres, the party amused all ages' neighbours (Wright, 2020).

The use of the front door space happened even without the presence of people. A resident in New Jersey found a message saying, "we're all in this together," with a rainbow painting on a front door in their neighbourhood. She appreciated the message and wrote that she would follow the neighbour and put the same sign on her door (Fullilove, 2020). Similar ways of using spaces in-between private and public spaces also happen in other cities in Europe, Australia, and other regions. An opera singer sang in a balcony in Milan, a resident in Melbourne placed a board with a cheering message on a sidewalk, and so forth.

\section{Outlining "porch placemaking"}

These similar cases emerged spontaneously in different cities and countries without any design guides or campaigns in a very early stage (i.e., March and April of 2020) because these actions were rooted in fundamental human needs. Schneider and Alderfer (1973) developed an existence, relatedness, and growth (ERG) model based on Maslow's hierarchy of needs. The model explains that many city dwellers now demand the existence need that contains a physiological need safety need in terms of the physical environment. At the same time, people have got aware that they are losing chances to satisfy the relatedness need that comes after the existence need. The above actions come out from this need to feel interpersonal connection and belongingness. This article labels these actions to fill the relatedness need in front of one's home as "porch placemaking." These actions have several key features of placemaking - a 
collaborative process in which people come together to create vital public spaces that bring health, happiness, and social connection to their communities (Project for Public Spaces, 2018).

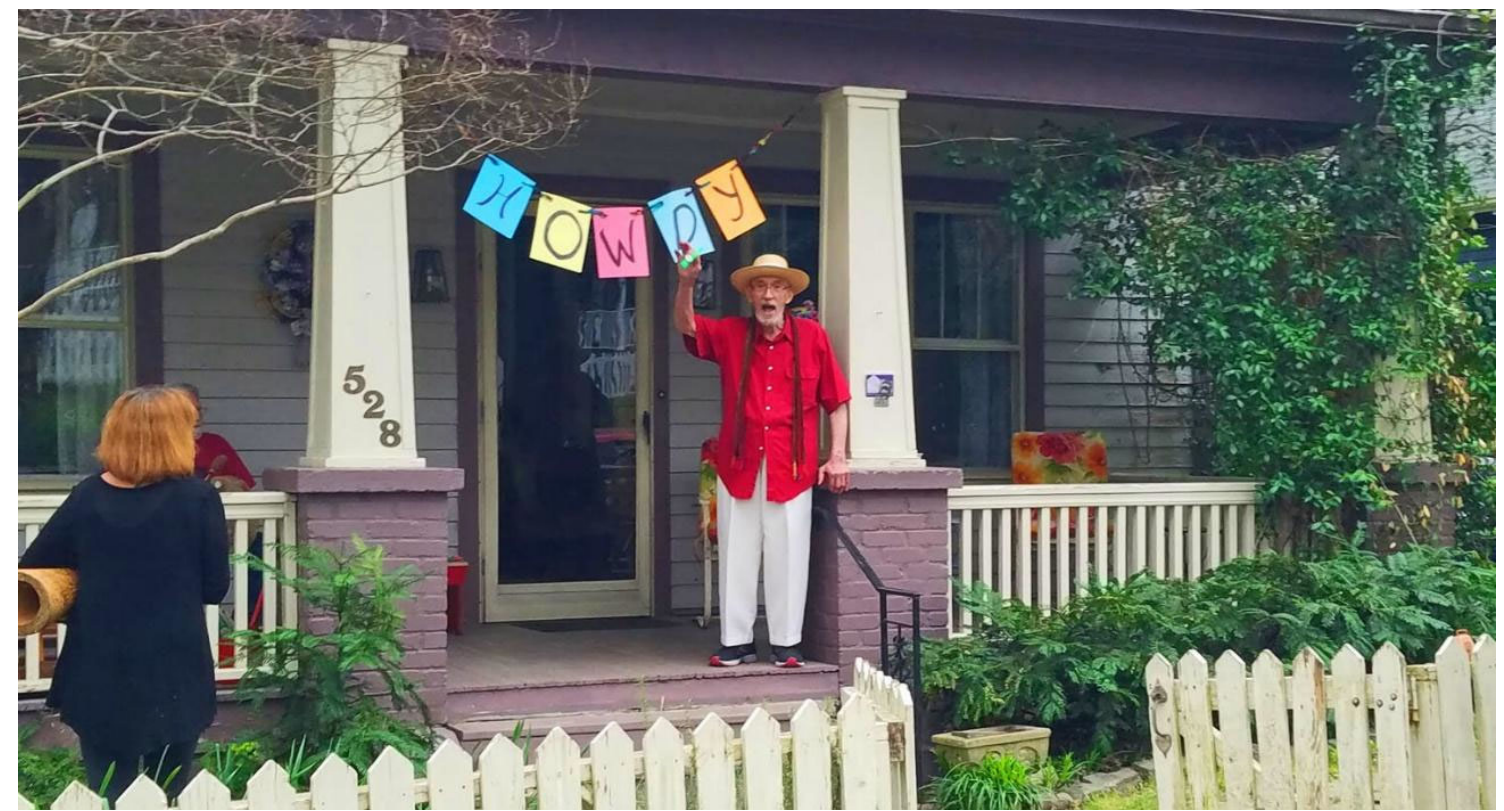

Figure I. People are singing and making musing in the Oakwood neighbourhood, Raleigh, NC. Photo: Tina Govan Architect, 2020.

More specifically, porch placemaking has the following characteristics.

- Creating social connection: porch placemaking practices have an intention to communicate with others, unlike purely personal use of the space. Moreover, they often induce neighbours to join the action.

- Quickly done on a micro-scale: "lighter, quicker, cheaper (LQC)" is one of the approaches characterizing placemaking, and porch placemaking is an extreme form of the manner. Porch placemaking usually happens with stuff available in one's home, and there is no thorough plan or preparation. This approach fits the circumstance when it is challenging to go shopping for new materials.

- Led by individuals and supported by communities: in other words, porch placemaking is not planned, advised, or financed by authorities or professionals. It is a spontaneous and self-motivated action for an implementor's common goods and his/her neighbours'.

There are three types of porch placemaking by how people are involved. The first one is a solo porch placemaking that randomly takes place by an individual or group. This type is not planned but spontaneously attracts the attention of passers-by and opens interactions. The second is a planned type like the case of the social distancing dance party. This type is more like an event and actively engaging neighbours. The third type does not need the presence or live-action of people in the space. Instead, they show a meaningful message and/or sign to communicate with others. 


\section{Spatial characteristics of porch placemaking}

Although this article calls "porch" placemaking, this concept intends to include actions happening in porch-like spaces such as balconies, windows, stoops, and front yards. The porch is not a universal format of architecture, but other cultures also have equivalent spaces. For instance, traditional Japanese houses have a space called "engawa", a wooden deck attached on the house's face just about a meter. The "fuzzy space" often functions as an interface of social communication with neighbours (Fujii, 20I5). In a blog post on porches, Architect Tina Govan points out that in-between spaces of public and private realms can be a porch:

"Whether it's balconies, porches, or stoops, these in-between spaces are essential and too often are omitted. I've never felt comfortable in buildings that don't offer this kind of transitional space, where there is an abrupt division between in and out, a black or white choice with no grey in-between. Porches offer us the freedom to choose where we want to be on the spectrum between inside and out, social or not. They create a soft edge, a kind of flexible connective tissue, that mediates between individual and community, and in these times, a safe way to maintain our social, mental and physical health."

(Govan, 2020)

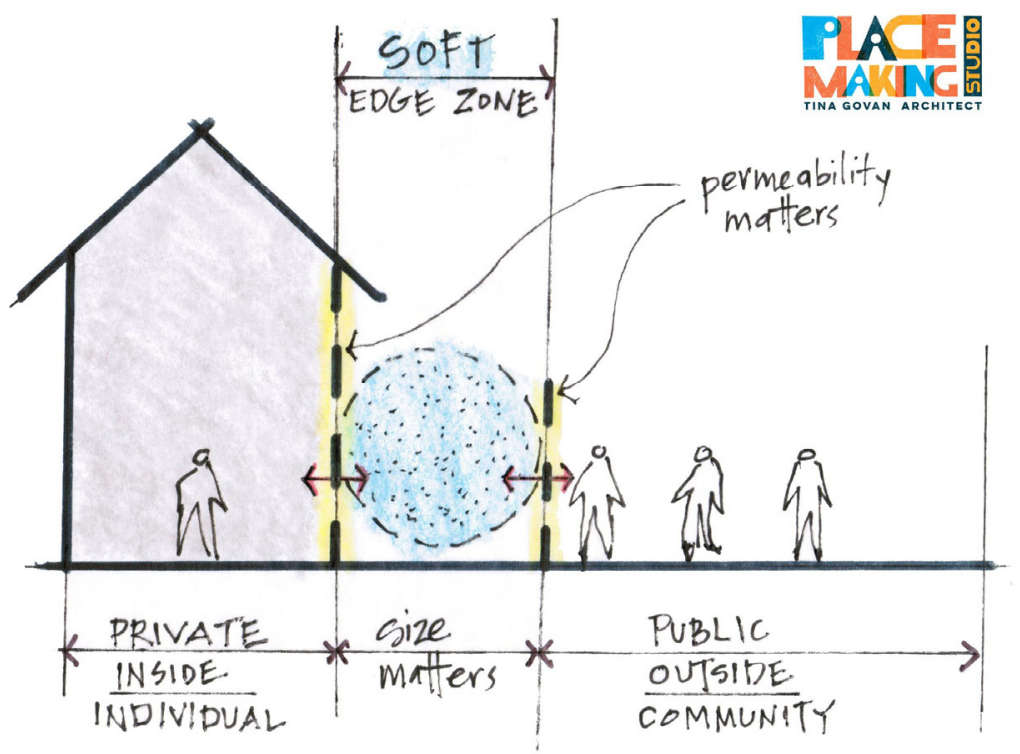

Figure 2. Soft edge at a porch between private and public spaces. Image: Tina Govan Architect.

Porches usually belong to a private property where residents can control and implement small interventions while they are visible from a street. This feature enables people to express their creativity in an LQC manner and spill it into the public realm. 


\section{Conditions for porch placemaking}

By collecting international cases of porch placemaking, authors find that it is active in some areas and not in others. It means that several conditions help porch placemaking. One is building and neighbourhood design. When there is no porch space or equivalent, it is not easy to take action. For instance, such spaces are not available in suburban neighbourhoods developed decades ago where a hard edge surrounds individual houses. Those bed town neighbourhoods follow the modern development idea prioritizing home security, single-use, and auto transport over walking. Traditional engawa spaces die out or hide behind a wall that distinctly divides private and public realms.

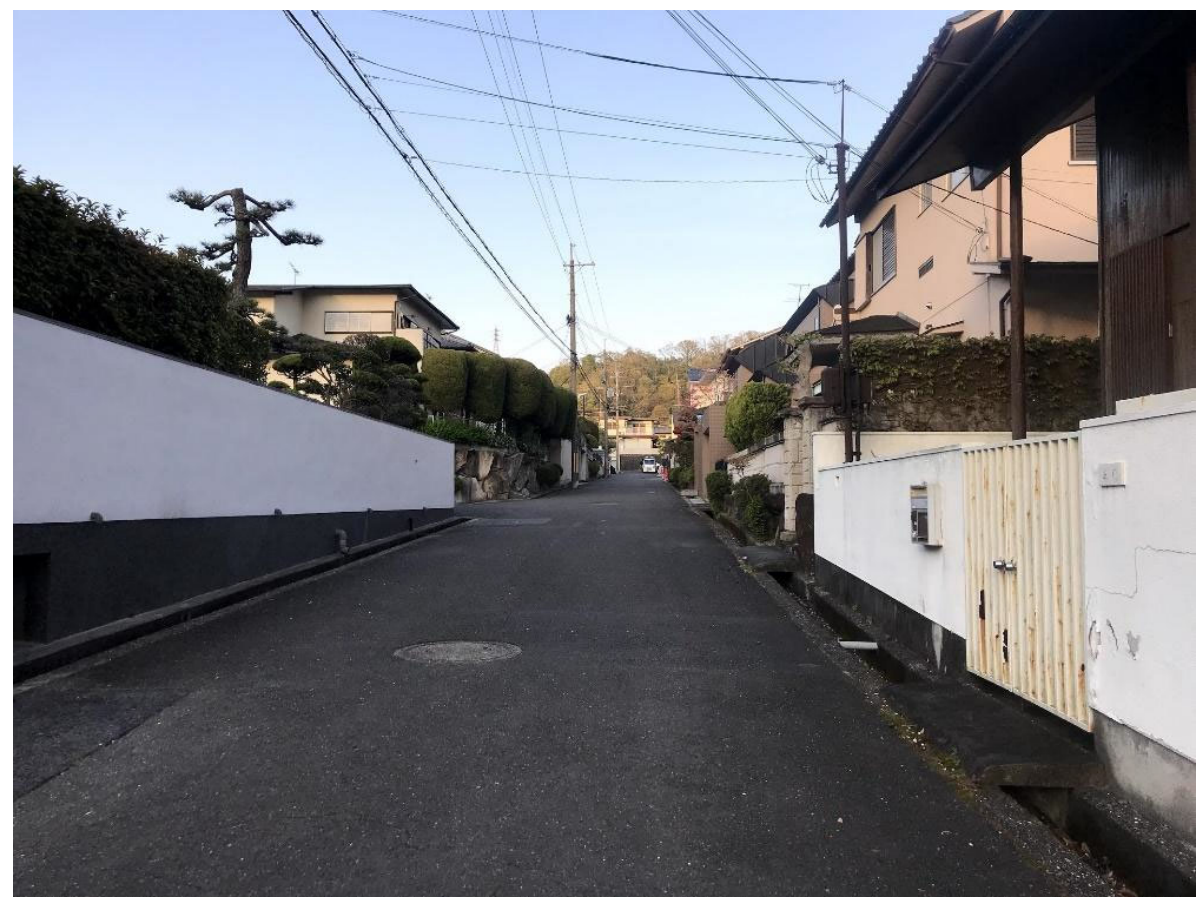

Figure 3. Hard edges in a bed town suburb in Japan. Photo: author.

Poon (2020) points out that a balcony, patio, deck, or porch is accessible by $62 \%$ of renters across the top 15 most populated metro areas in the United States. According to her analysis of the housing survey, wealthier renters tend to access the space. Another condition is the density and building scale of the neighbourhood. Porch placemaking usually happens in an urban or suburban area with a certain level of density, and it is deemed not as active in a less dense rural area. On the other hand, it is also difficult for residents in a high riser in a dense area to communicate with people on the ground level from their balcony.

Additionally, there is a non-physical condition. People are likely to take a porch placemaking action when they share the same level of difficulty staying home at the same time of a day. This condition is not a case in Japanese cities because the government does not have the legislative power to enforce staying home but only to request it. Due to this loose movement restriction, a certain number of workers kept commuting and did not spend time around home.

Thus, grounds for porch placemaking are visibility or communicability between private and public spaces, extent of freedom to use such in-between spaces (i.e., porches), 
presence of a certain number of people in proximity in same time of a day and sharing desire to socialize.

\section{Porch placemaking week - a global movement to amplify the impact}

An Australian placemaking group, Codesign Studio, organized the initiative of "porch placemaking week" from May $30^{\text {th }}$ to June $5^{\text {th }}$ of 2020 to share global practices on an online platform. This campaign aimed to deepen the discussion and help communities to keep benefitting from micro-scale placemaking. This movement was formed with over 200 porch placemaking projects across 23 countries from every continent in the world. Participants posted their interventions on a Facebook group during the week and shared their thoughts in a series of online forums.

There was no rigid criteria or requirement for registering a project as porch placemaking. Instead of defining the concept distinctly, this campaign explored various ways to apply porch placemaking by cultural and design contexts of different countries and neighbourhoods through crowdsourced actions. Eventually, registered interventions varied in scale, location, purpose, groups involved, and type of activities.

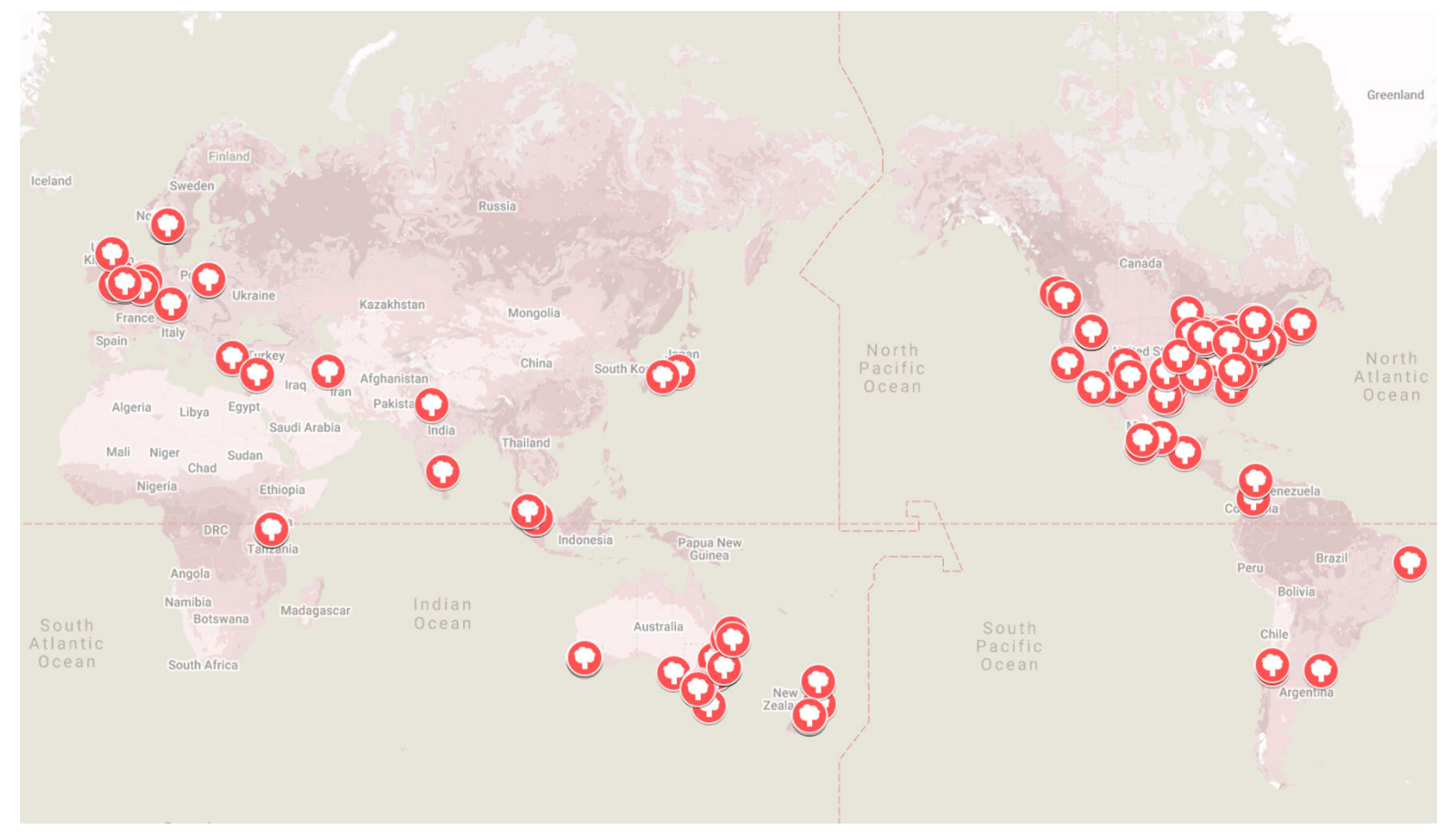

Figure 4. Projects registered in the porch placemaking week 2020. Image: web site of porch placemaking week 2020.

One notable finding in this global action is that porch placemaking is not only for residents of a house with a porch in wealthy countries but for those who live in informal settlements or densely populated cities. For instance, in Nairobi, Kenya, local artists joined the movement by painting visual messages that encourage infection control behaviours on housing walls in a slum. 


\section{Effectiveness of porch placemaking - during and after the pandemic}

Although there is no rigorous survey or data of influences brought by porch placemaking, images of actions usually come with positive statements about increased social interaction and mental refreshment during a hard time. Some report that they had more chances to communicate and know their neighbours than ever by using their porch.

O'Sullivan (2020) collected actions happening in-between spaces in the article titled "Alone Together, in Community Resilience." According to the article, "cohesive communities where neighbours check in on neighbours" is part of urban resilience. Porch placemaking contributes to enhancing community cohesion.

Porch placemaking possibly has short-term impacts during the pandemic and indirect impacts in the long run. Practices of porch placemaking may shift their behaviour and social life in the outdoor space by making them aware of possible ways to use spaces, their desire for social wellbeing, and the people around them. Moreover, it may affect an approach of architectural and neighbourhood design.

\section{Way forward to expand and sustain actions}

Since porch placemaking is an emerging concept, further case studies and examinations are necessary to take insights for design, planning, and policy to respond to urban issues and maintain community resilience in the future.

There is a possibility to support and expand small-scale individual actions at a porch by a campaign like the porch placemaking week. Another interesting case is the "Uchi Hana" project initiated by Ikoma city, Japan. The project is to distribute nursery flowers to households to place the flowers in front of their house. The city tied the project with the concept of porch placemaking to encourage citizens to make streets active.

\section{Acknowledgment}

This article received tremendous inspiration and contribution from Tina Govan and a forum discussion with her and international participants at the second online Placemaking Forum. An online visual presentation and discussion of these ideas by her and the author is viewable on the Placemaking Forum's Facebook page.

Also, the initiators and collaborators of the porch placemaking week played a vital role in testing and developing the emerging concept, which brought rich sources and insights. 
Porch Placemaking

\section{References}

Fujii, M. (2015) Urban Engawa / Veranda -Making Interactive Spaces for Tokyo Urbanites in the Fuzzy Spaces between Inside and Outside-. Thesis. Available at: https://digital.lib.washington.edu:443/researchworks/handle/I773/33987 (Accessed: 18 March 202I).

Fullilove, M. T. (2020) 'Coronavirus: This new togetherness', Countdown to Main Street, April. Available at: https://mainstreetnj.blogspot.com/2020/04/this-new-togetherness.html (Accessed: I 4 May 2020).

Govan, T. (2020) In Praise of Porches During Covid-19, PLACEMAKING STUDIO. Available at: http://tinagovan.com/lifeofplaces/2020/3/3I/in-praise-of-porches-during-covid-19 (Accessed: 13 May 2020).

O'Sullivan, F. (2020) Alone Together, in Community Resilience, CityLab. Available at: https://www.citylab.com/life/2020/03/coronavirus-alone-together-community-resilienceneighbors/608374/ (Accessed: I 3 May 2020).

Poon, L. (2020) A Lesson from Social Distancing: Build Better Balconies, CityLab. Available at: https://www.citylab.com/life/2020/04/apartment-design-balcony-private-outdoor-spacezoning-laws/610162/ (Accessed: 13 May 2020).

Project for Public Spaces (2018) How to Turn a Place Around: A Placemaking Handbook. 2nd edition. Project for Public Spaces.

Schneider, B. and Alderfer, C. P. (1973) 'Three Studies of Measures of Need Satisfaction in Organizations', Administrative Science Quarterly, I8(4), pp. 489-505.

Wright, M. (2020) New York residents throw a 'social distancing dance party', Mail Online. Available at: https://www.dailymail.co.uk/news/article-8167949/New-York-residents-throw-socialdistancing-dance-party-bust-Rolling-Stones.html (Accessed: I 4 May 2020). 